\section{P1-473 ASSESSING THE PSYCHOSOCIAL IMPACT OF DENTAL OUTCOMES ON CHILDREN AND PARENTAL QUALITY OF LIFE}

doi:10.1136/jech.2011.142976g.62

\begin{abstract}
${ }^{1} \mathrm{~A} M$ Cascaes, ${ }^{*}{ }^{2} \mathrm{~K}$ G Peres, ${ }^{2} \mathrm{M}$ A Peres, ${ }^{1} \mathrm{~F}$ Demarco, ${ }^{1}$ I Santos, ${ }^{1} \mathrm{~A}$ Matijasevich, ${ }^{1}$ A J D Barros. 'Federal University of Pelotas, Pelotas, Rio Grande do Sul, Brazil; ${ }^{2}$ Federal University of Santa Catarina, Florianópolis, Santa Catarina, Brazil
\end{abstract}

Introduction Dental diseases and disorders can negatively impact on the quality of life of preschool children and their families. Socioeconomic and demographic characteristics may confound those effects, but this issue has been scarcely studied in this age group. Objective To evaluate the effects of untreated dental caries, dental pain and malocclusions on the oral health-related quality of life (OHRQoL) of 5-years-old children and their families, adjusting for mothers' schooling, household income, sex and children skin colour. Methods A subsample of 1129 children from the 2004 Pelotas, Brazil, Birth Cohort study, was investigated in 2009. Children were dentally examined and their mothers were interviewed at home. The outcome, OHRQoL, was assessed by the Brazilian version of Early Childhood Oral Health Impact Scale (ECOHIS) using child and parental subscales and total scores as discrete variables. Multivariable Poisson regression models were performed to estimate the association between the outcome and the co-variates.

Results The multivariable adjusted model showed that dental pain had a great impact on child (IRR $4.5095 \%$ CI 3.58 to 5.65) and parental (IRR $3.0595 \%$ CI 2.25 to 4.13 ) quality of life. The severity of high levels of untreated dental caries had also a negative impact on children (IRR $2.0195 \%$ CI 1.56 to 2.59) and their family (IRR $3.7595 \%$ CI 2.58 to 5.45 ) quality of life. Malocclusions had impact only on the total score (IRR $1.3295 \%$ CI 1.09 to 1.60) and the family subscale (IRR $1.4095 \%$ CI 1.08 to 1.81).

Conclusions Dental problems were associated with lower scores of OHRQoL of children and their families regardless potential confounders.

\section{P1-474 TOOTH LOSS IN BRAZILIAN MIDDLE-AGED ADULTS: THE INFLUENCE OF INDIVIDUAL AND CONTEXTUAL FEATURES}

doi:10.1136/jech.2011.142976g.63

${ }^{1} \mathrm{R}$ Moreira, ${ }^{2} \mathrm{~L}$ Barrozo, ${ }^{2} \mathrm{~J}$ Pereira. ${ }^{1}$ Oswaldo Cruz Foundation, Ministry of Health, Recife, Pernambuco, Brazil; ${ }^{2}$ Universidade de São Paulo, São Paulo, Brazil

Introduction The demographic and epidemiological transitions are causing changes in the health profile worldwide. Among the various areas of healthcare, oral health is in a precarious situation. The objective was to examine the link between tooth loss and multilevel factors in a national sample of middle-aged adults in Brazil.

Methods Analyses were based on the 2003 cross-sectional national epidemiological survey of the oral health of the Brazilian population, which covered 13431 individuals (age 35-44 years). Multistage cluster sampling was used. The dependent variable was tooth loss and the independent variables were classified according to the individual or contextual level. A multilevel negative binomial regression model was adopted.

Results The average tooth loss was 14 teeth. Half of the individuals had lost 12 teeth. The contextual variables showed independent effects on tooth loss. It was found that having 9 years or more of schooling was associated with protection against tooth loss (means ratio range $0.68-0.76$ ). Not having visited the dentist and not having visited in the last 3 years accounted for increases of $33.5 \%$ and $21.3 \%$, respectively, in the risk of tooth loss. The increase in tooth extraction ratio showed a strong contextual effect on increased risk, besides changing the effect of protective variables.
Conclusion Tooth loss in middle-aged adults has important associations with social determinants of health. This study points to the importance of the social context as the main cause of oral health injuries suffered by most middle-aged Brazilian adults.

\section{P1-475 PSYCHO-SOCIAL FACTORS AND LEGAL STATUS OF MTP SERVICES: A BASIC HINDRANCE FOR ACCEPTANCE OF SERVICES IN RURAL AREA OF CENTRAL INDIA}

doi:10.1136/jech.2011.142976g.64

A Mudey, ${ }^{*}$ M Khapre, V Wagh, R Goyal. Jawaharlal Nehru Medical College, Sawangi (Meghe), Wardha, Maharashtra, India

Introduction Approximately 46 million abortions were performed worldwide in 1995. Of these, about 26 million were legal and 20 million illegal. There is a great paucity on status of knowledge of community regarding MTP and mainly from rural area. So the present study was carried out in rural area to highlight some reasons for under-utilisation of MTP service.

Methods Study was carried in a PHC, attached to tertiary care rural teaching hospital consisting of ten villages with total population of 14722. Sample size calculated on basis of findings in pilot study. After systematic random sampling of household, 1271 women gave consent, 113 who undergone safe abortion was identified and both the groups were compared for social, psychological, economic, cognitive and affective factors related to abortion.

Result Young age, marital status, literacy, parity $>2$, higher social class were significantly associated with abortion service seekers. Significant difference was found in awareness and attitude towards abortion in above two groups. $85 \%$ women felt abortion should be accepted socially. $8.8 \%$ abortees had made the self decision, $40.7 \%$ and $43 \%$ got the social and economic support respectively. Precounselling done in $37 \%$, while service was not affordable for $35 \%$. Conclusion Unawareness about the MTP services and its legal status is basic hindrance for acceptance of service along with illiteracy, low socio-economic status, fear of disapproval, lack of privacy and complication related anxiety attached to it. Abortion services are not accessible, affordable to many, and insensitive to women's psychological need.

\section{P1-476 AN ASSESSMENT OF THE CONCENTRATION-RELATED PROGNOSTIC VALUE OF CARDIAC TROPONIN I IN 1285 PATIENTS FOLLOWING ACUTE CORONARY SYNDROME}

doi:10.1136/jech.2011.142976g.65

${ }^{1,2} \mathrm{C}$ P Gale, ${ }^{1} \mathrm{E}$ Metcalfe, ${ }^{1,3} \mathrm{~A}$ D Simms, ${ }^{1} \mathrm{R}$ West, ${ }^{3} \mathrm{C}$ Morrell, ${ }^{1} \mathrm{~T}$ Munyombwe, ${ }^{*}$ ${ }^{1} \mathrm{~W}$ Harrison, ${ }^{4} \mathrm{P} \mathrm{D}$ Batin, ${ }^{3} \mathrm{~A}$ S Hall, ${ }^{1} \mathrm{~J} \mathrm{H}$ Barth. ${ }^{1}$ Centre for Epidemiology and Biostatistics, University of Leeds, Leeds, UK; ${ }^{2}$ Department of Cardiology, York Teaching Hospital NHS Foundation Trust, York, UK; ${ }^{3}$ Yorkshire Heart Centre, Leeds Teaching Hospitals NHS Trust, Leeds, UK; ${ }^{4}$ Department of Cardiology, Mid-Yorkshire Hospitals NHS Trust, Wakefield, UK; ${ }^{5}$ Department of Biochemistry, Leeds Teaching Hospitals NHS Trust, Leeds, UK

Introduction The British Cardiac Society, in 2004, redefined myocardial infarction by troponin concentration: $c T n I \leq 0.06 \mu \mathrm{g} / 1$ (unstable angina), cTnI $>0.06 \mu \mathrm{g} / 1$ to $<0.5 \mu \mathrm{g} / 1$ (myocardial necrosis), and $c T n I \geq 0.5 \mu \mathrm{g} / \mathrm{l}$ (myocardial infarction). We investigated the effects of this classification on all cause mortality. Methods Survival analysis of 1285 patients from the EMMACE-2 registry.

Results 528 deaths ( 6.6 year all cause mortality $=41.1 \%$ ). Survival was greatest in the $c \operatorname{TnI} \leq 0.06 \mu \mathrm{g} / \mathrm{l}$ subgroup at 30 days $(\mathrm{p}=0.005)$, 6 months $(p=0.015), 1$ year $(p=0.002)$ and at 6.6 years $(p=0.045)$. After adjustment there was no statistically significant difference in 